Relations industrielles

Industrial Relations

\title{
Index 1948-1949
}

Volume 4, numéro 10, juin 1949

URI : https://id.erudit.org/iderudit/1023548ar

DOI : https://doi.org/10.7202/1023548ar

Aller au sommaire du numéro

\section{Éditeur(s)}

Département des relations industrielles de l’Université Laval

ISSN

0034-379X (imprimé)

1703-8138 (numérique)

Découvrir la revue

Citer ce document

(1949). Index 1948-1949. Relations industrielles / Industrial Relations, 4(10),

100-100. https://doi.org/10.7202/1023548ar

Tous droits réservés ( $@$ Département des relations industrielles de l’Université Laval, 1949
Ce document est protégé par la loi sur le droit d'auteur. L'utilisation des services d'Érudit (y compris la reproduction) est assujettie à sa politique d'utilisation que vous pouvez consulter en ligne.

https://apropos.erudit.org/fr/usagers/politique-dutilisation/ 


\section{INDEX $1948-1949$}

Arbitrage, La procédure d' - No 8, avril, p. 78.

Assermenter les témoins?, Qui doit - Marie-Louis Beaulieu, No 5 , janvier, p. 45 .

Bill 5, Documentation relative au - No 7, mars, p. 68.

Capitalisme, l'Eglise et le - Comte della Torre, No 9, mai, p. 90 .

Code du travail, Documentation relative au Bill 5 , No 7 , mars, p. 68.

Chefs ouvriers en sessions d'études, - Marcel de la Sablonnière, No 3, novembre, p. 23.

Confédération des travailleurs catholiques du Canada, La Alfred Charpentier, No 1, septembre, p. 3.

Congés annuels payés édictés par décrets, Les (Loi de la convention collective) - Charles Bélanger, No 7, mars, p. 66.

Congé des employés pour voter à une élection - No 9 , mai, p. 88.

Congrès canadien du travail, Le - Eugène Forsey, No 1, septembre, p. 5.

Congrès, Profils de notre quatrième, - Gérard Tremblay, No 6, février, p. 51.

Conseil d'entreprise - No 8, avril, p. 75.

Contrat de travail, La rupture du - Georges-Michel Giroux, No 9, mai, p. 83.

Conventions collectives dans le Québec, Les - La Direction, No 4, décembre, p. 31 .

Convention collective et administration du personnel, Application de la - Jean Gagné, No 8, avril, p. 73.

Convention collective de travail, Visée d'avenir sur la Jacques Archambault, No 10, juin, p. 98.

Délai-congé, Le, - No 8, avril, p. 78.

Directeur du personnel S.V.P., Un, - Gérard Tremblay, No 2, octobre, p. 15

Economie doit être placée au service de l'homme, L' Paul-H. Plamondon, No 10, juin. p. 97.

Education de la C.T.C.C., Le service d' - Fernand Jolicoeur, No 6, février, p. 58.

Eglise et le capitalisme, L' - Comte della Torre, No 9, mai, p. 90.

Entreprise, Le droit des travailleurs de participer activement à la vie de l' - Mgr P. Pavan, No 1, septembre, p. 10.

Entreprise libérale à la libre entreprise, De l' - Marcel Clément, No 2, octobre, p. 11.

Evêque social, Un - T.R.P. Georges-Henri Lévesque, o.p., No 1 , septembre, p. 1 .

Formation professionnelle dans l'industrie de l'imprimerie de Montréal, Economie du régime de - Marcel Forget, No 5, janvier, p. 43.

Formation professionnelle dans l'industrie de l'imprimerie de Montréal, Programme de - Marcel Forget, No 7, mars, p. 63.

In Memoriam: Egbert Munzer - Léon Dion, No 1, septembre, p. 2.

Indice du coût de la vie au ler septembre 1948 a été calculé, Comment l' - No 3 , novembre, p. 26.
Indice du coût de la vie et les réclamations de salaire, $L^{\prime}$ - Jean-Marie Martin, No 5, janvier, p. 41.

Juridiction pour décider des moyens de droit présentés au cours de l'arbitrage par l'une des parties? Les arbitres ont-ils - No 2 , octobre, p. 20.

Loi fédérale des relations de travail, La nouvelle - Denys Dion, No 3, novembre, p. 30.

Loi de la convention collective, L'avenir de la - No 4 décembre, p. 34 .

Loi de la convention collective, Propos du lecteur: L'avenir de la - No 6, février, p. 59.

Loisirs et relations de travail, - Louise Dumais, No 3, novembre, p. 27

Métiers du bâtiment, Les jeunes et les - Marcel Clément, No 6, février, p. 53.

Métiers qui meurent dans l'industrie du bâtiment, Les Marcel Clément, No 10, juin, p. 94.

On nous écrit, - No 5 , janvier, p. 50 .

Patrons, Directives aux - S.S. Pie XII, No 9, mai, p. 81.

Problème social, L'Eglise catholique et le - Marcel Clément, No 7 , mars, p. 61 .

Réformes de structure, Les, - No 8, avril, p. 78 .

Réformes de structures et syndicalisme. - Marcel Clément, No. 3, novembre, p. 21.

Relations industrielles, L'Université Laval et les - Gérard Dion, No 4, décembre, p. 32.

Relations industrielles dans l'usine organisée, Les - W.E. Curry, No 4, décembre, p. 38.

Relations de travail, Techniques des - Quatrième Congrès des relations industrielles de Laval, No 7, mars, p. 70.

Relations de travail, Techniques des - Gérard Tremblay. No 8 , avril, p. 71 .

Relations de travail, Statistiques des - No 9, mai, p. 89.

Relations de travail, Statistiques des - No. 5, janvier, p. 47.

Salaires minima dans l'industrie du bâtiment, Mouvement des - Gérard Roy, No 4, décembre, p. 36.

Salaires, Le budget familial et les réclamations de - JeanMarie Martin, No 6, février, p. 52.

Salaires dans le commerce de l'alimentation en gros de Québec, Mouvement des - Raymond Gagné, No 8, avril, p. 76.

Sciences sociales et l'homme, Les - Hon. Antonio Barrette, No 2, octobre, p. 17.

Sécurité syndicale dans la Province de Québec, La, Gérard Dion, No 5, janvier, p. 48.

Sécurité syndicale en Angleterre, La - Gérard Dion, No 6 , février, p. 57.

Sécurité syndicale, La légalité des clauses de - LouisPhilippe Pigeon, No 10, juin, p. 91.

Témoins, Qui doit assermenter les? - Marie-Louis Beaulieu, No 5, janvier, p. 45.

Thèses en relations industrielles présentées pour l'obtention de la maîtrise en sciences sociales, No 9, mai, p. 89 .

Université Laval au Service du peuple, $L^{\prime}-$ No 2, octobre, p. 19. 